\title{
Effects of Delayed First Feeding on Larval Growth and Survival of Yesso Scallop (Patinopecten yessoensis)
}

\author{
Zhongqiang $\mathrm{Cai}^{1}$, Xiujun $\mathrm{Sun}^{2} \&$ Aiguo Yang ${ }^{2}$ \\ ${ }^{1}$ Changdao Enhancement and Experiment Station, Chinese Academy of Fishery Sciences, Changdao, China \\ ${ }^{2}$ Key Laboratory of Sustainable Development of Marine Fisheries, Ministry of Agriculture, Yellow Sea Fisheries \\ Research Institute, Chinese Academy of Fishery Sciences, Qingdao 266071, China \\ Correspondence: Xiujun Sun, Key Laboratory of Sustainable Development of Marine Fisheries, Ministry of \\ Agriculture, Yellow Sea Fisheries Research Institute, Chinese Academy of Fishery Sciences, Qingdao, China. \\ E-mail: xjsun@ysfri.ac.cn
}

Received: June 20, 2014 Accepted: July 4, 2014 Online Published: July 7, 2014

doi:10.5539/ijb.v6n4p37 URL: http://dx.doi.org/10.5539/ijb.v6n4p37

\begin{abstract}
The time of first feeding is an important factor for establishing successful initial feeding in molluscan hatcheries. The effects of delayed first feeding on larval growth and survival in the larvae of Yesso Scallop Patinopecten yessoensis were investigated in this study. Groups of larvae were fed at early stage of D-shaped larvae or delayed for $24,48,72,96,120$ and $144 \mathrm{~h}$. When first feeding was delayed for less than $72 \mathrm{~h}$, the $P$. yessoensis larvae grew as rapidly as those non-starved larvae. When delayed first feeding for more than $72 \mathrm{~h}$, the growth rates of larvae were significantly reduced (less than $2 \mu \mathrm{m} \mathrm{day}^{-1}$ ), half or less than those of the non-starved group. The survival rates decreased sharply with the prolonged starvation period and the extremely low survival rates were observed in the groups that were delayed first feeding for more than $72 \mathrm{~h}$. The results indicate that the prolonged starvation had a deleterious impact on the larval growth and survival when delayed first feeding for $96 \mathrm{~h}$ or more. To avoid mass mortality and obtain adequate growth and survival, food availability within $72 \mathrm{~h}$ after early D-shaped larvae is critical important for the successful initial feeding in commercial culture of this species.
\end{abstract}

Keywords: Patinopecten yessoensis, delayed first feeding, growth, survival rate

\section{Introduction}

For marine invertebrates, factors influencing larval survival are predation, starvation, and oceanographic conditions that may transport larvae into unfavorable environments by advection (Sewell et al., 2004). During planktonic period, larvae acquire their food from seawater to get energy for growth and development, and starvation has long been considered to be an important source of mortality of marine invertebrate larvae (Thorson, 1950; Manahan, 1990; Wehrtmann, 1991). Newly hatched planktotrophic larvae have very little nutrient reserves, so the availability of food in the first few days after hatching is critical for their survival (Pawlik, 1992). The amount of phytoplankton in the ocean is rarely present at concentrations necessary to sustain maximum larval growth, which indicates planktonic larvae have the potential to be food-limited in nature and experience high mortality when encountering adverse feeding conditions (Olson \& Olson, 1989; Fenaux et al., 1994). In order to better understand the effects of starvation or food limitation on larval growth, survival and development in marine invertebrates, laboratory experiments were widely performed in a variety of species (His \& Seaman, 1992; Pedrotti \& Fenaux, 1993; Fenaux et al., 1994; McEdward \& Qian, 2001; Moran \& Manahan, 2004; Yang et al., 2008).

The Yesso scallop Patinopecten yessoensis is a cold water bivalve and naturally distributes along the coastline of the northern islands of Japan, northern Korean Peninsula, and Russian Primorye, Sakhalin and Kurile islands (Ito, 1991). Because P. yessoensis is larger in size and has higher market values than the native Zhikong scallop Chlamys farreri, it has become one of the most important maricultural shellfish in northern China since it was introduced in 1982. Artificial seed production is critically important for the aquaculture industry for the reason that $P$. yessoensis seeds are produced exclusively in hatcheries in China. In commercial shellfish hatcheries, cultured live microalgae are mainly used as the diets for bivalve larvae. However, microalgal production is time consuming and limited by culture conditions and apparatus, and the culture of microalgae can be subject to various types of contamination, resulting in sudden mortality or unsuitability as a food source (Robert \& Trintignac, 1997). For that reason, the supply of microalgae in hatcheries is often insufficient to meet the requirements of a large-scale, 
commercial shellfish breeding. Larvae are potentially at risk of starvation especially when several batches of larvae are reared in hatcheries. Therefore, a greater understanding of the effects of starvation on larvae will assist in the development of adequate feeding management for batches of larvae in a food-limited situation.

Previous studies on P. yessoensis have investigated in the aspects of artificial seed production and culture (Zhang et al., 2000), polyploidy induction (Yang et al., 2001), interspecific hybridization (Yang et al., 2004), and population genetics (Li et al., 2007). However, little information is available at present to understand the effects of starvation on the scallop larvae. We therefore investigated the effects of delayed first feeding on growth and survival of $P$. yessoensis larvae, in order to better understand starvation tolerance of this species, and provide information for the successful establishment of exogenous feeding schedules for hatcheries.

\section{Materials and Methods}

\subsection{Larval Culture}

Adults of Yesso Scallop P. yessoensis were collected from the coast of Zhangzidao Island, Liaoning Province, China. Animals were maintained at $6-8{ }^{\circ} \mathrm{C}$ in $10 \mathrm{~m}^{3}$ concrete tanks by changing seawater daily and fed Nitzschia closterium f. minutissima and Spirulina Platensis for about 30 days to speed up their gonad development. Before spawning, the males were removed from the culture tank and transferred to 100-L containers. Broodstock scallops were dried for 1-2 $\mathrm{h}$, and then moved to higher temperature sand-filtered seawater $\left(10^{\circ} \mathrm{C}\right)$ to induce spawning. After the release of eggs, sperm were added to the spawning tank to assure that the sperm/egg ratio was about 5:1. During the incubation, continuous aeration was accomplished by air flow through a series of air stones distributed evenly in the bottom of the tank. When the zygotes developed to early D-shaped larvae (about $72 \mathrm{~h}$ after fertilization) at which time they were ready to feed on algae, the larvae were siphoned and isolated on $60-\mu \mathrm{m}$ sieve for counting and used in starvation experiments.

\subsection{Starvation Experiments}

Eight different levels of starvation were tested (larvae were starved for 0, 24, 48, 72, 96, 120, $144 \mathrm{~h}$, and unfed group). Three replicates were used for each treatment. In $0 \mathrm{~h}$ group, larvae were fed immediately after the

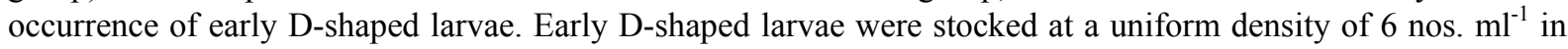
plastic circular aquarium barrels containing 3-L sand-filtered seawater. The experiment was conducted at a temperature of $10 \pm 2{ }^{\circ} \mathrm{C}$ under an ambient photoperiod regime of $14 \mathrm{~h}$ of light and $10 \mathrm{~h}$ of dark. Culture water was exchanged for $1 / 2$ twice a day. The algal diet of Isochrysis galbana was provided at an initial density of 5000 cells ml ${ }^{-1}$ day $^{-1}$, progressively increased to $20000 \mathrm{cells} \mathrm{ml}^{-1}$ day ${ }^{-1}$, and Platymonas subcordiformis at a density of 2000 cells ml$^{-1}$ day $^{-1}$ were used for the late stage of larval development.

\subsection{Larval Growth of Shell Length and Shell Width, Larval Survival}

The shell length and shell width of larvae in different treatments were measured using a microscope with a pre-calibrated micrometer at 100× magnification. Larval measurements were made on days 5, 8, 12, 16, 23 after early D-shaped larvae. The growth rates $(n=24$ larvae/treatment) were calculated by regressing direct measurements of larval length and width over the culture days. To determine the survival rate of larvae, three $20-\mathrm{ml}$ or $40-\mathrm{ml}$ subsamples were randomly taken from each replicate, and the numbers of larvae were counted using a microscope on days 6, 9, 13, 17, and 24 .

\subsection{Statistical Analysis}

One-way ANOVA was performed to test the effects of starvation on shell length and width of larvae in different treatments. Post-hoc tests (Tukey HSD) were performed in order to test the differences among groups. The significant levels for the growth and survival rates among groups were also determined by One-way ANOVA followed by Tukey HSD test. All statistical analyzes were conducted with the SPSS 17.0 program. Statements of significant differences were based on accepting $P<0.05$.

\section{Results}

\subsection{Effects of Delayed First Feeding on the Growth of Shell Length}

The growth of larval shell length in different treatments during culture days are shown in Figure 2. For all treatment groups, the obvious increases in shell length were observed from day 0 to day 5 . On day 5 , the larvae in the different treatment groups had the same value of shell length $(120.98 \pm 1.62 \mu \mathrm{m} ; F=1.218, \mathrm{df}=7,12$, $P>0.05)$. In contrast, the significant differences in shell length were observed among groups on day $8(F=14.46$, $\mathrm{df}=7,11, P<0.01)$. The relatively higher values in shell length were observed in 0 and $24 \mathrm{~h}$ groups, with the maximum value of $127.60 \pm 0.63 \mu \mathrm{m}$ in $24 \mathrm{~h}$ group, which are significantly higher than those of 48, 72, 96, $120 \mathrm{~h}$ and unfed groups (Tukey's HSD test, $P<0.05$ ). The significant differences in shell length among groups were also 
observed on day $12(F=6.40, \mathrm{df}=7,10, P<0.01)$, while no significant difference were detected on day 16 $(F=2.51, \mathrm{df}=7,11, P>0.05)$. On day 12, the maximum value of shell length was also observed in $24 \mathrm{~h}$ group $(145.98 \pm 0.66 \mu \mathrm{m})$, which was significantly higher than that in $96 \mathrm{~h}, 120 \mathrm{~h}$, and unfed groups. From day 16 to day 23 , the remarkable growth in shell length were observed in $0,24,48,72 \mathrm{~h}$ groups, but no survived larvae were detected in the groups that were starved for $96 \mathrm{~h}$ or more on day 23 .

After feeding, larvae that had been starved for $24 \mathrm{~h}$ had mean growth rates of $3.71 \pm 0.06 \mu \mathrm{m} \mathrm{day}^{-1}$ by day 12 , growing as rapidly as larvae in the 0,48 and $72 \mathrm{~h}$ group, with the growth rates of $2.56 \pm 0.18 \mu \mathrm{m} \mathrm{day}^{-1}, 2.69 \pm 0.18$ $\mu \mathrm{m} \mathrm{day}{ }^{-1}$, and $2.39 \pm 0.01 \mu \mathrm{m} \mathrm{day}^{-1}$, respectively (Table 1). The growth rates for $96,120 \mathrm{~h}$ and unfed groups were less than $2 \mu \mathrm{m} \mathrm{day}^{-1}$, which were significantly affected by delayed first feeding. From day 12 to day 23 , the growth rates of larvae in the groups that were delayed first feeding for less than $72 \mathrm{~h}$ were significantly higher than those of groups that were fed after periods of starvation for $96 \mathrm{~h}$ and more (Tukey's HSD test, $P<0.05$ ).

Table 1. Mean growth rates of shell length and shell width in different treatments $(0,24,48,72,96,120,144 \mathrm{~h}$ and unfed) during culture days. Values with different letters are significantly different from each other $(P<0.05)$

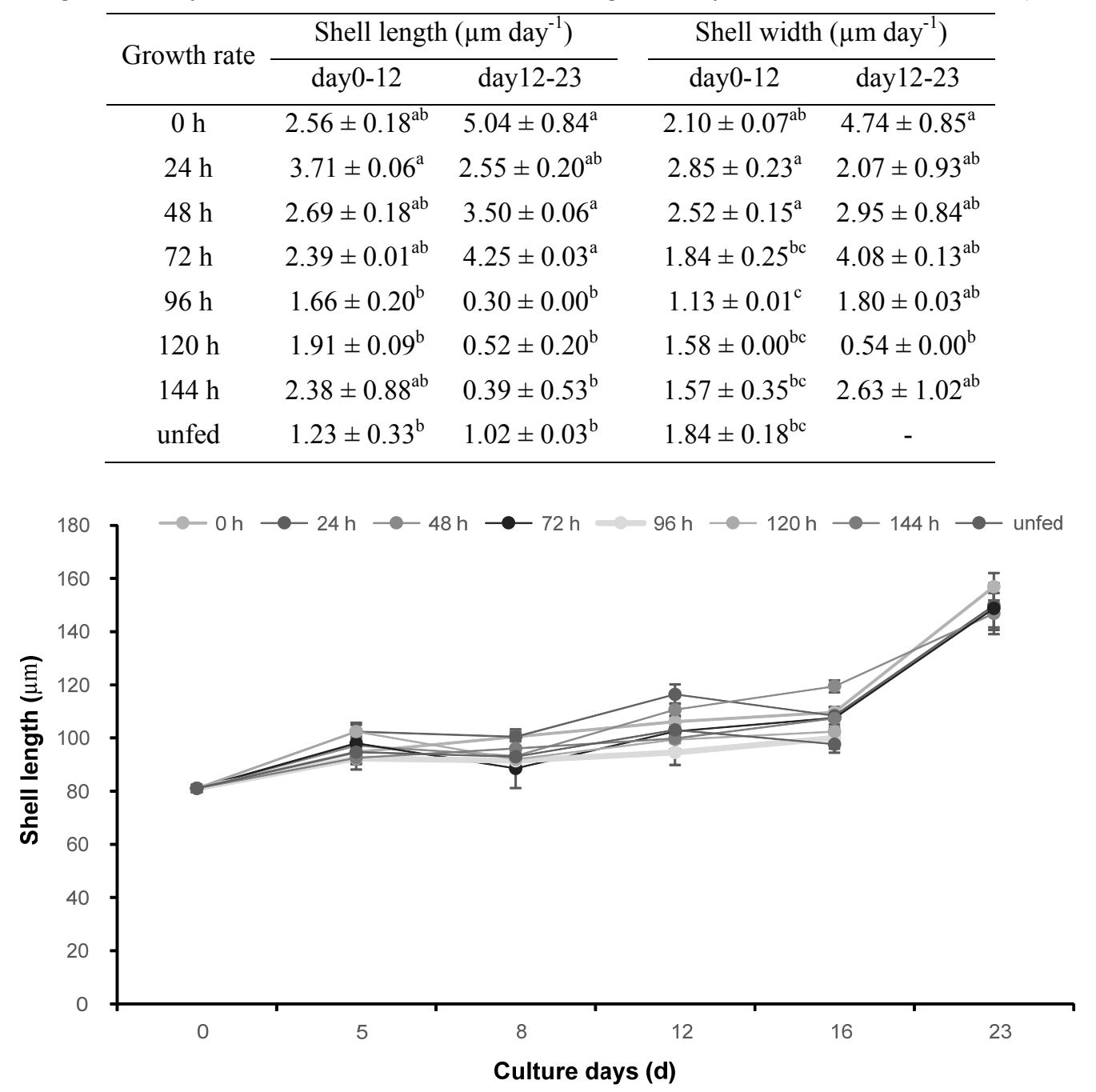

Figure 1. Mean shell length of Patinopecten yessoensis in different groups (delayed first feeding for 0, 24, 48, 72, 96,120 , and $144 \mathrm{~h}$, and unfed group) during culture days. All error bars represent standard error of the mean

\subsection{Effects of Delayed First Feeding on the Growth of Shell Width}

The growth of larval shell width in different treatments during culture days are shown in Figure 2. On day 5 and day 8 , there was no significant difference in shell width among groups $(F=0.63, \mathrm{df}=7,12, P>0.05 ; F=1.63$, $\mathrm{df}=7,11, P>0.05)$, while the significant differences were detected on day $12(F=8.04, \mathrm{df}=7,10, P<0.01)$. On 
day 12 , the maximum shell length was observed in $24 \mathrm{~h}$ group, $115.19 \pm 2.77 \mu \mathrm{m}$, which was not significant but higher than that of $0 \mathrm{~h}$ group. The significantly lower values in shell width were observed in groups that were starved for $96 \mathrm{~h}$ and more, having $94.58 \pm 0.17 \mu \mathrm{m}$ in $96 \mathrm{~h}$ group, $100.04 \pm 0.03 \mu \mathrm{m}$ in $120 \mathrm{~h}$ group and $99.86 \pm 4.23 \mu \mathrm{m}$ in $144 \mathrm{~h}$ group, respectively (Tukey's HSD test, $P<0.05$ ). On day 16 , there were significant differences observed in shell width among groups $(F=4.58, \mathrm{df}=7,11, P<0.05)$. The maximum shell width was detected in $48 \mathrm{~h}$ group, with the value of $119.51 \pm 2.33 \mu \mathrm{m}$, which was significantly higher than that of $96,120 \mathrm{~h}$ and unfed groups. The remarkable growth in shell width were observed in $0,24,48,72 \mathrm{~h}$ groups, however, no data was recorded in 96, 120, 144 and unfed groups because no survived larvae were found in those groups on day 23.

For the growth rates of shell width by day 12 , the growth advantage was observed in the groups that were starved for $48 \mathrm{~h}$ and less (Table 1). In contrast, the growth rates were significantly negatively affected by delayed first feeding for $72 \mathrm{~h}$ or more, with less than $2 \mu \mathrm{m} \mathrm{day}^{-1}$ (Tukey's HSD test, $P<0.05$ ). Although the highest growth rate of $4.74 \pm 0.85 \mu \mathrm{m} \mathrm{day}^{-1}$ occurred in $0 \mathrm{~h}$ group, the slight differences had been observed among other groups except for $120 \mathrm{~h}$ group (Tukey's HSD test, $P>0.05$ ).

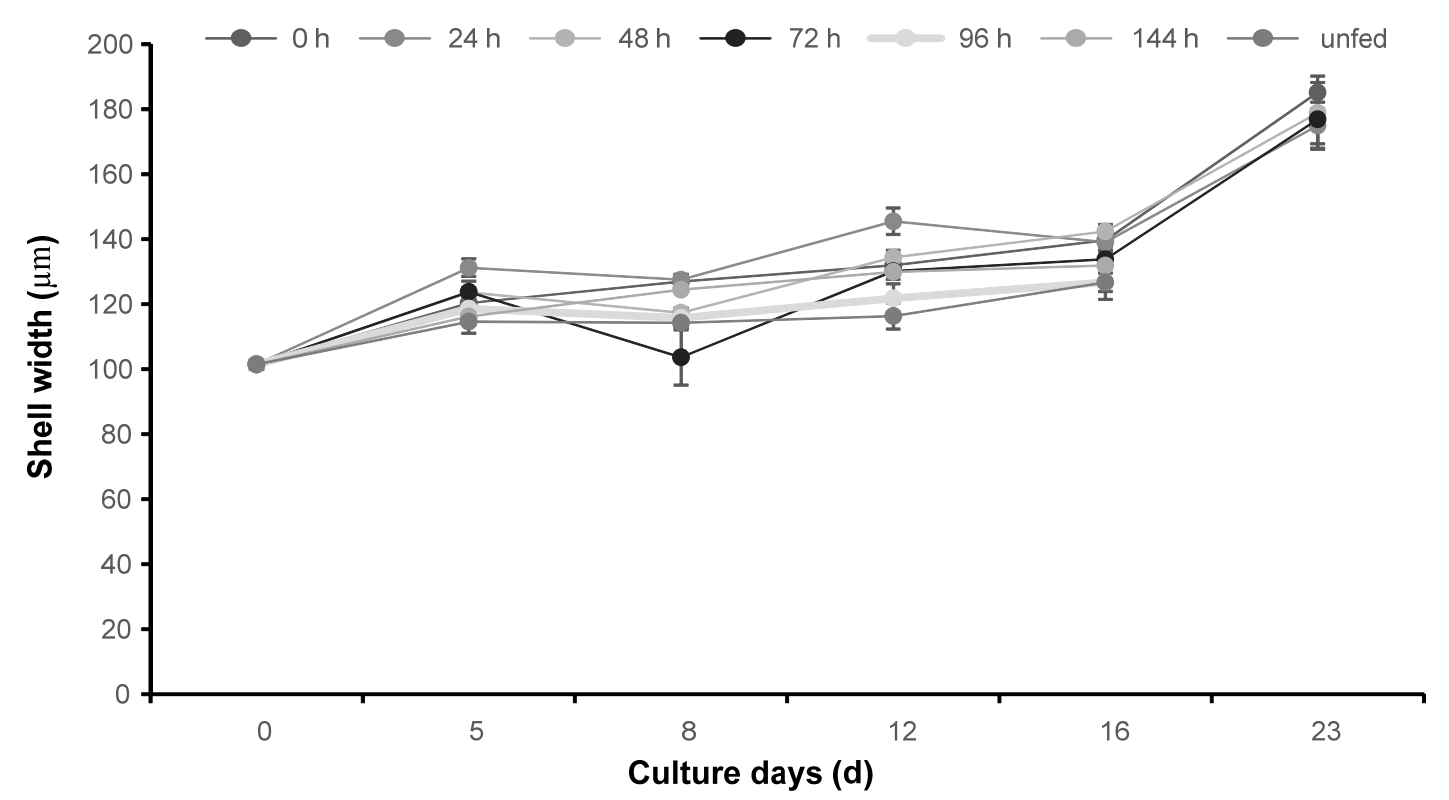

Figure 2. Mean shell width of $P$. yessoensis in different groups (delayed first feeding for $0,24,48,72,96,120$ and $144 \mathrm{~h}$, and unfed group) during culture days. All error bars represent standard error of the mean

\subsection{Effects of Delayed First Feeding on Larval Survival}

The survival rates of larvae in different groups are shown in Figure 3. The significantly lower survival rates were observed on all counting days except for day 17, showing steeping declines over the time period (Tukey's HSD test, $P<0.05$ ). By day 6 , the survival rates decreased sharply with the prolonged starvation period especially in the groups that were starved for $96 \mathrm{~h}$ and more, lower than $20.0 \%$, compared to the maximum survival rate of $58.3 \%$ in $0 \mathrm{~h}$ group. This suggests that delayed first feeding in P. yessoensis larvae had a deleterious impact on the larvae when delayed first feeding for $96 \mathrm{~h}$ and more. In contrast, no significant difference was detected among $0,24,48$, and $72 \mathrm{~h}$ groups (Tukey's HSD test, $P>0.05$ ). On day 9 , the maximum survival rate was observed in $24 \mathrm{~h}$ group, which was significantly higher than those of the groups that were starved for $72 \mathrm{~h}$ and more (Tukey's HSD test, $P<0.05$ ). On day 13 , no significant difference in survival rate was detected among $0,24,48$, and $72 \mathrm{~h}$ groups, significantly higher than those of $96,120,144 \mathrm{~h}$ and unfed groups. On day 24 , there was no significant difference in survival rates among 24,48 , and $72 \mathrm{~h}$ groups, and the highest survival rate $(4.17 \%)$ was observed in $0 \mathrm{~h}$ group. Moreover, most larvae starved for $72 \mathrm{~h}$ and more were delayed in development, subsequently becoming deformed before they reached umbo larvae stages. 


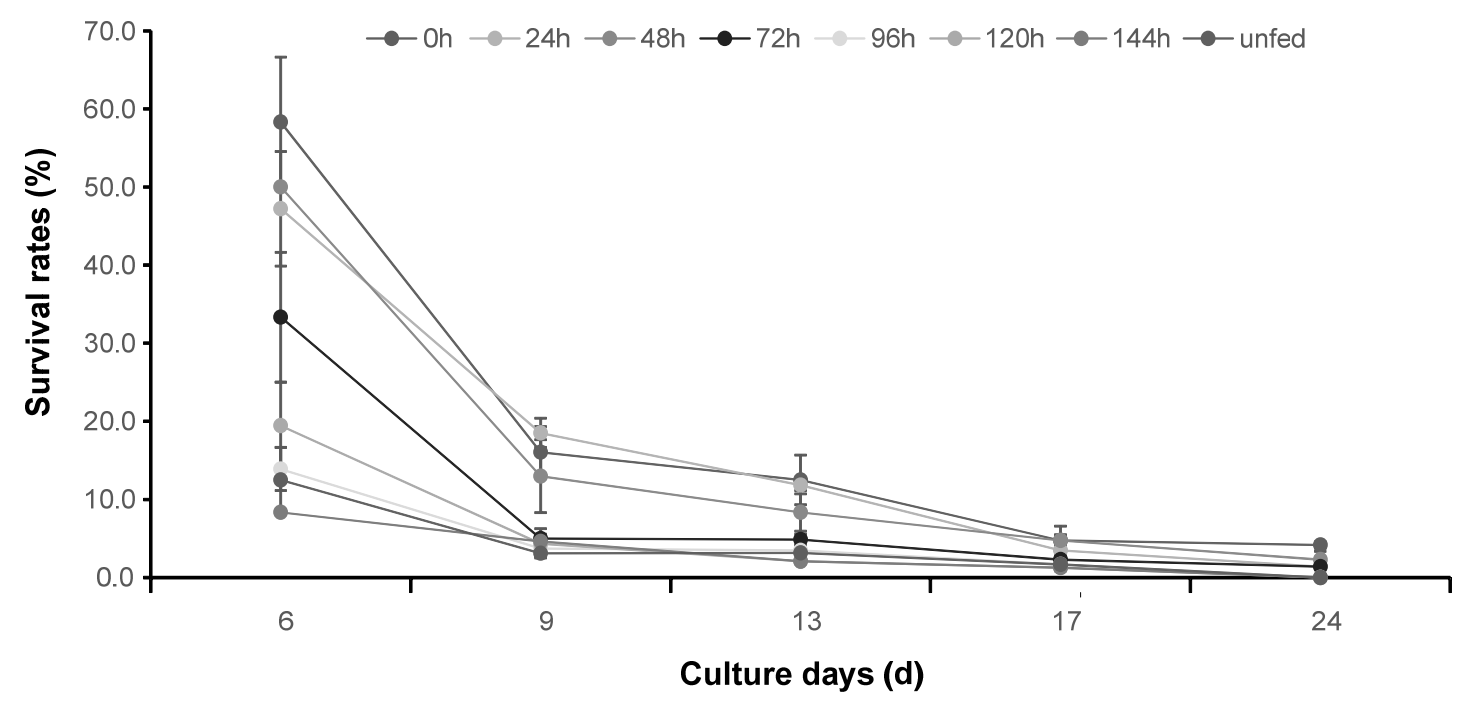

Figure 3. Mean survival rates of $P$. yessoensis larvae in different groups (delayed first feeding for $0,24,48,72,96$, 120 , and $144 \mathrm{~h}$, and unfed group) during culture days

\section{Discussion}

The different responses of larval growth and survival when larvae were exposed to different durations of starvation prior to first feeding indicate that the first feeding time had significant effects on $P$. yessoensis larvae. For marine invertebrates, larvae depend largely on their endogenous yolk reserves to support the energy for developing the feeding ability and physiological mechanisms, which will help to start the normal first feeding, growth and survival (Olson \& Olson, 1989). Previous studies on delayed first feeding or starvation in early larval development may have profound effects on subsequent larval growth, development, and survival (Zheng et al., 2005; Tang et al., 2006; Yan et al., 2009). In the present study, when delayed first feeding for 24, 48 and $72 \mathrm{~h}$, the growth rates of $P$. yessoensis larvae following short periods of starvation recovered to the level of the non-starved larvae. However, when larvae were fed after being starved for more than $72 \mathrm{~h}$, growth rates were significantly smaller, half or less than the growth of the control group. Similarly, growth recovery of larvae for short-duration starvation was observed in Ivory shell Babylonia formosae habei (Zheng et al., 2005), Manila clam Ruditapes philippinarum (Yan et al., 2009), and hard clam Meretrix meretrix (Tang et al., 2006). The possible explanations for the ability of larvae to achieve normal growth after short periods of starvation are mainly attributed into three parts. First, larvae might respond to starvation by feeding more vigorously at higher rates or more continuously. Second, larvae might respond to food concentration by altering the allocation of resources between growth and development (Bertram \& Strathmann, 1998). As reported, starved larvae of sea cucumber increase the allocation of growth to the ciliated band when feeding is resumed, and therefore they are capable of acquiring more food (Sun \& Li, 2014). In this study, the greater sizes in shell length of larvae when delayed first feeding for $24 \mathrm{~h}$ suggest that the starved larvae might increase the ability of larval cilia to collect and ingest food particles. Third, starvation early in life might cause significant mortality and select for very hardy larvae that have inherently greater capacity for feeding and growth (McEdward \& Qian, 2001).

However, for the larvae starved for more than $72 \mathrm{~h}$, growth became significantly slower and never recovered to the level of non-starved larvae. It is suggested that starvation reduced larval growth rates largely by increasing the duration of the larval period relative to the opportunities for acquiring food (McEdward \& Qian, 2001). The prolonged starvation may cause permanent detrimental damage on larval feeding ability, such as the ability of larval cilia to collect and ingest food particles, and further inhibit energy generation for continuing development (Zheng et al., 2005). The irreversible damage on the starved larvae in this study was likely to be responsible for the low survival rates in those groups that were delayed first feeding for $96 \mathrm{~h}$ or more. For the crab Hyas araneus, when an early larva is starved beyond the critical point, its feeding ability will diminish and eventually experience irreversible damage to the mitochondria and hepatopancreas (Storch \& Anger, 1983). It is therefore assumed that extended starvation has a significant impact on larval feeding and digestion, resulting in a rapid degeneration progress of tissues, slow growth and mass mortality (Sun \& Li, 2014). Thus, the optimum starvation period for $P$. yessoensis larvae was $72 \mathrm{~h}$ or less after early D-shaped larvae, in order to avoid permanent detrimental effects on larvae due to starvation. 
For larvae of marine invertebrates, endogenous reserves are always insufficient to account for metabolic demand, and energy for larval development and metamorphosis are mainly from exogenous food (Bertram \& Strathmann, 1998). Therefore, the ability to withstand starvation in early larval development varies from species to species mostly depending on their endogenous reserves. For instance, sea star larvae could survive more than 70 days of starvation in early development (Allison, 1994). In contrast, the survival rate of sea cucumber larvae decreased markedly with prolonged starvation, and most larvae were dead after 13 days of starvation (Sun \& Li, 2014). Moderate effects on the survival rate of clam larvae (70.83\%) were observed during starvation for up to 9 days (Tang et al., 2006). Planktotrophic larvae of sea urchin could survive 14 days when a source of exogenous energy was not present (Meyer et al., 2007). In this study, the survival rates decreased sharply with the prolonged starvation period and eventually more than $98 \%$ of starved larvae were dead on day 19 after hatching. Those differences in starvation tolerance among species are probably attributed to nutrition content inside their egg capsules, such as nutritive fluids and yolk material (Pechenik, 1986; Chaparro et al., 1999). Besides the initial endogenous energy reserves, the variability of starvation tolerance among species may also be correlated with alternative sources of exogenous resources, such as dissolved organic material (DOM) or detritus in seawater. It is suggested that those materials are potentially important sources of energy for marine invertebrate larvae during starvation (Gomme, 2001; Moran \& Manahan, 2004; Sun \& Li, 2014). In this study, because the larvae were reared in sand-filtered seawater, DOM, probably not detritus, was more likely to provide a supplementary source of energy to maintain basic metabolism for the starved larvae, extending the larval period to 19 days after hatching. However, little is known about whether DOM is used differentially by marine benthic invertebrates (McEdward 1997; Moran \& Manahan, 2004).

In conclusion, the growth and survival rates of $P$. yessoensis larvae could recover to the level of the non-starved larvae when delayed first feeding for $72 \mathrm{~h}$ or less, while it had a deleterious impact on the larval growth and survival when delayed first feeding for $96 \mathrm{~h}$ or more. Food availability within $72 \mathrm{~h}$ after early D-shaped larvae plays a key role in the successful initial feeding for this species and establishment of exogenous feeding schedules for hatcheries.

\section{Acknowledgements}

This work is supported by The Key Laboratory of Mariculture (KLM), Ministry of Education, OUC, and the grants from Independent Innovation Funds of Shandong Province (2013CXC80202), and Emerging Strategic Industries Project of Qingdao City (13-4-1-60hy), and Special Scientific Research Funds for Central Non-profit Institutes, Yellow Sea Fisheries Research Institutes (20603022013012).

\section{References}

Allison, G. W. (1994). Effects of temporary starvation on larvae of the sea star Asterina miniata. Marine Biology, 118, 256-261. http://dx.doi.org/10.1007/BF00349792

Bertram, D. F., \& Strathmann, R. R. (1998). Effects of maternal and larval nutrition on growth and form of planktotrophic larvae. Ecology, 79, 315-327. http://dx.doi.org/10.1890/0012-9658(1998)079\%5B0315: EOMALN\%5D2.0.CO;2

Chaparro, O. R., Oyarzun, R. F., Vergara, A. M., \& Thompson, R. J. (1999). Energy investment in nurse eggs and egg capsules in Crepidula dilatata Lamarck (Gastropoda, Calyptraeidae) and its influence on the hatching size of juvenile. Journal of Experimental Marine Biology and Ecology, 232, 261-277. http://dx.doi.org/10.1016/S0022-0981(98)00115-4

Fenaux, L., Strathmann, M. F., \& Strathmann, R. R. (1994). Five tests of food-limited growth of larvae in coastal waters by comparisons of rates of development and form of echinoplutei. Limnology and Oceanography, 39, 84-89. http://dx.doi.org/10.4319/lo.1994.39.1.0084

Gomme, J. (2001). Transport of exogenous organic substances by invertebrate in teguments: the field revisited. Journal of Experimental Zoology, 289, 254-265. http://dx.doi.org/10.1002/1097-010X(20010401/30)289:4\% 3C254::AID-JEZ6\%3E3.0.CO;2-F

His, E., \& Seaman, M. N. L. (1992). Effects of temporary starvation on the survival, and on subsequent feeding and growth, of oyster (Crassostrea gigas) larvae. Marine Biology, 114, 277-279. http://dx.doi.org/10.1007/B F00349530

Ito, H. (1991). Patinopecten (Mizuhopecten) yessoensis. In S. E. Shumway (Ed.), Scallops: Biology, Ecology and Aquaculture. Elsevier, Amsterdam (pp. 1024-1055). 
Li, Q., Xu, K. F., \& Yu, R. H. (2007). Genetic variation in Chinese hatchery populations of the Japanese scallop (Patinopecten yessoensis) inferred from microsatellite data. Aquaculture, 269, 211-219. http://dx.doi.org/10. 1016/j.aquaculture.2007.04.017

Manahan, D. T. (1990). Adaptations by invertebrate larvae for nutrient acquisition from seawater. American Zoologist, 30, 147-160.

McEdward, L. R., \& Qian, P. Y. (2001). Effects of the duration and timing of starvation during life on the metamorphosis and initial juvenile size of the polychaete Hydroides elegans (Haswell). Journal of Experimental Marine Biology and Ecology, 261, 185-197.

McEdward, L. R. (1997). Reproductive strategies of marine benthic invertebrates revisited: facultative feeding by planktotrophic larvae. American Zoologist, 150, 48-72.

Meyer, E., Green, A. J., Moore, M., \& Manahan, D. T. (2007). Food availability and physiological state of sea urchin larvae (Strongylocentrotus purpuratus). Marine Biology, 152, 179-191. http://dx.doi.org/10.100 7/s00227-007-0672-6

Moran, A. L., \& Manahan, D. T. (2004). Physiological recovery from prolonged 'starvation' in larvae of the Pacific oyster Crassostrea gigas. Journal of Experimental Marine Biology and Ecology, 306, 17-36. http://dx.doi. org/10.1016/j.jembe.2003.12.021

Olson, R. R., \& Olson, M. H. (1989). Food limitation of planktrophic marine invertebrate larvae: does it control recruitment success? Annual Review of Ecology and Systematics, 20, 225-247.

Pawlik, J. R. (1992). Chemical ecology of the settlement of benthic marine invertebrate. Oceanography and Marine Biology: an annual review, 30, 273-335.

Pechenik, J. A. (1986). The encapsulation of eggs and embryos by molluscs: an overview. American Malacological Bulletin, 4, 165-172.

Pedrotti, M. L., \& Fenaux, L. (1993). Effects of food diet on the survival, development and growth rates of two cultured echinoplutei (Paracentrotus lividus and Arbacia lixula). Invertebrate Reproduction \& Development, 24, 59-70. http://dx.doi.org/10.1080/07924259.1993.9672332

Robert, R., \& Trintignac, P. (1997). Substitutes for live microalgae in mariculture. Aquatic Living Resources, 10, 315-327. http://dx.doi.org/10.1051/alr:1997035

Sewell, M. A., Cameron, M. J., \& McArdle, B. H. (2004). Developmental plasticity in larval development in the echinometrid sea urchin Evechinus chloroticus with varying food ration. Journal of Experimental Marine Biology and Ecology, 309, 219-237. http://dx.doi.org/10.1016/j.jembe.2004.03.016

Storch, V., \& Anger, K. K. (1983). Influence of starvation and feeding on the hepatopancreas of larval Hyas araneus (Decapoda, Majidae). Helgoländer Meeresuntersuchungen, 36, 67-75. http://dx.doi.org/10.1007/B F01995796

Sun, X. J., \& Li Q. (2014). Effects of delayed first feeding on larval growth, survival and development of the sea cucumber Apostichopus japonicus (Holothuroidea). Aquaculture Research, 45, 278-288. http://dx.doi.org/10. $1111 / \mathrm{j} .1365-2109.2012 .03224 . x$

Tang, B. J., Liu, B. Z., Wang, G. D., Zhang, T., \& Xiang, J. H. (2006). Effects of various algal diets and starvation on larval growth and survival of Meretrix meretrix. Aquaculture, 254, 526-533. http://dx.doi.org/10.1016/j. aquaculture.2005.11.012

Thorson, G. (1950). Reproductive and larval ecology of marine bottom invertebrates. Biological Reviews, 25, 1-45. http://dx.doi.org/10.1111/j.1469-185X.1950.tb00585.x

Wehrtmann, I. S. (1991). How important are starvation periods in early larval development for survival of Crangon septemspinosa larvae? Marine Ecology Progress Series, 73, 183-190. http://dx.doi.org/10.3354/me ps073183

Yan, X. W., Zhang, Y. H., Huo, Z. M., Yang, F., \& Zhang, G. F. (2009). Effects of starvation on larval growth, survival, and metamorphosis of Manila clam Ruditapes philippinarum. Acta Ecologica Sinica, 29, 327-334. http://dx.doi.org/10.1016/j.chnaes.2009.09.012

Yang, A. G., Wang, Q. Y., Liu, Z. H., \& Zhou, L. Q. (2004). The hybrid between the scallops Chlamys farreri and Patinopecten yessoensis and the inheritance characteristics of its first filial generation. Marine Fisheries Research, 25, 1-5. 
Yang, F., Zhang, Y. H., Yan, X. W., \& Zhang, G. F. (2008). Effects of starvation and refeeding on larval growth, survival, and metamorphosis of clam Cyclina sinensis. Acta Ecologica Sinica, 28, 2052-2059.

Yang, H., Li, L., \& Guo, X. M. (2001). Preliminary study on inducing polyploidy in Japanese scallop (Patinopecten yessoensis) by cytochalasin B. Acta Zoologica Sinica, 47, 459-464.

Zhang, Q., Zhang, Q., Li, W., \& Wang, X. (2000). Study on high yield technology of raft culture of Patinopecten yessoensis. Marine Science, 24, 14-16.

Zheng, H. P., Zheng, C. H., Zhou, S. L., \& Li, F. X. (2005). Effects of starvation on larval growth, survival and metamorphosis of Ivory shell Babylonia formosae habei Altena et al., 1981 (Neogastropoda: Buccinidae). Aquaculture, 243, 357-366. http://dx.doi.org/10.1016/j.aquaculture.2004.10.010

\section{Copyrights}

Copyright for this article is retained by the author(s), with first publication rights granted to the journal.

This is an open-access article distributed under the terms and conditions of the Creative Commons Attribution license (http://creativecommons.org/licenses/by/3.0/). 